\title{
Exploring the Relationship between Social Capitals and English Language Achievement within a Specific Grade and Context
}

\author{
Ebrahim Khodadady (Corresponding author) \\ Ferdowsi University of Mashhad, Mashhad, 91779-48883, Iran \\ Tel: 98-91-5157-0733 E-mail: ekhodadady@gmail.com
}

Reza Pishghadam

Ferdowsi University of Mashhad

E-mail: rpishghadam@yahoo.com

Farnaz Farokh Alaee

Ferdowsi University of Mashhad

E-mail: farnaz.alaee@yahoo.com

Received: February 18, 2012

Accepted: March 8, 2012

Published: May 1, 2012

doi:10.5539/elt.v5n5p45

URL: http://dx.doi.org/10.5539/elt.v5n5p45

\begin{abstract}
An achievement test based on schema theory (S-Test) was developed on the passages comprising the English textbook taught at grade three in state high schools in Iran and administered concurrently with a validated and reliable Social Capital Scale (SCS) to four hundred seventy seven male and female participants. The Z-scores obtained on the S-Test were utilized to divide the participants into high, middle and low achievers. Among the ten factors underlying the SCS, i.e., Self Volunteering, Receptive Relatives, Maternal Supervision, Parental Monitoring, Teacher Consultation, Parental Expectation, Parental Rapport, Family Religiosity, Helpful Others and Parent Availability, high achievers' Family Religiosity correlated significantly with their S-Test whereas a significant correlation was found between Parental Monitoring and S-Test for middle achievers, indicating that social capitals of these two ability groups function differently. The results also showed while middle achievers' scores on the semantic subtest of S-Test related significantly and positively to Parental Monitoring, Teacher Consultation and Family Religiosity, they correlated significantly but negatively with Parental Expectation and Helpful Others on the syntactic subtest. The semantic subtest also revealed the highest significant and negative relationship with low achievers' Teacher Consultation. The findings are discussed and suggestions are made for future research.
\end{abstract}

Keywords: Social capitals, Achievement, S-Test, Foreign language

\section{Introduction}

Schools are social institutions where the adolescent and young members of a given society such as the residents of Mashhad in Iran are trained and educated to live and work together as harmoniously as possible. Scholars in various fields of human knowledge such as applied linguistics, education, and psychology believe that the very variable of living together within a society endows its members with various capitals to fulfill their personal needs and obtain academic objectives. A relatively large number of social capitals have thus been specified by these scholars.

Among others, Onyx and Bullen (1998), for example, brought up being socially responsible, calling friends and relatives, and teachers' role as social capital indicators. Blaxter et al (2001) pointed out being valued by society, and social satisfaction. Garmoran and Lopez (2007) focused on expressing feelings while Israel, Beaulieu, and Hartless (2001) emphasized extent of parental acquaintance with other people. Parcel and Dufur (2001) singled out family cohesion whereas Stanton-Salazar, and Dornbusch (1995) highlighted friends' expectations.

Muller (2001) and Hughes (1995), however, draw researchers' attention to school environment and school quality, respectively. Carmo (2010) maintained the importance of social integration and Dyk and Wilson (1999) referred to trusting people as important indicators of social capitals. While Bianchi and Robinson (1997) brought up visiting grandparent, Morrow (2001) identified visiting relatives and neighbours as important. To make the list of social 
capitals as comprehensive as possible Hao and Bonstead-Burns (1998) directed their attention to students' participation in extracurricular activities whereas Smith, Beaulieu and Israel (1992) stressed religious involvement.

The core of human society is family and this is reflected in the identification of mothers' attendance of school meetings (e.g., Pong, 1998), mothers' familiarity with children's friends (e.g., McNeal, 1999), parent-child talk (e.g., Yan, 1999), parents being at home (e.g., Morgan, \& Scrensen, 1999), parents' control (e.g., White, \& Glick, 2000), parents' educational encouragements (e.g., Furnstenberg \& Hughes, 1995), parents' expectations (e.g., Carbonaro, 1998; Muller, \& Ellison, 2001), parents' help with the homework (e.g., Wright, Cullen, \& Miller, 2001), and parents' keeping track of their children's progress (e.g., Lopez, 1996) as the most significant social capitals in the literature.

Khodadady and Alaee (2012) converted the above specified indicators of social capitals into a 40-item Social Capital Scale (SCS) and administered it to one thousand three hundred and fifty two grade three high school students in Mashhad, Iran. By utilizing the Principal Axis Factoring (PAF) method and rotating the latent variables via Varimax with Kaiser Normalization they extracted ten rotated factors, i.e., Self Volunteering, Receptive Relatives, Maternal Supervision, Parental Monitoring, Teacher Consultation, Parental Expectation, Parental Rapport, Family Religiosity, Helpful Others, and Parent Availability. The present study is designed to find out whether the SCS and its ten factors show any significant relationship with grade three high school students' achievement in English taught as a foreign language in a specific educational district in Iran.

\section{Methods}

\subsection{Participants}

Among the eleven educational districts in Mashhad, Iran, district four was chosen randomly. Based on the information gathered from the Bureau of Education in the same city, it includes 19 boys and 34 girls' schools accommodating 3909, 2596 female and 1313 male, grade three high school students. In order to have a more homogeneous sample it was arbitrarily decided that only state schools be included in the study and thus their number was reduced to eight boys and 16 girls' high schools from which seven schools were chosen for having more students and being located in different parts of the district. Out of two thousand two hundred and sixteen, 743 male and 1473 female, students studying in the state schools of district four, 477, $151(31.7 \%)$ male and $326(68.3 \%)$ female, students voluntarily took part in the study. Their age ranged between 16 and $18(\mathrm{M}=17.24, \mathrm{SD}=.50)$. They spoke Persian as their mother language. (Three participants were, however, excluded from correlational analyses because they did not take either the S-Test or SCS.)

\subsection{Instruments}

A test and a questionnaire were developed and employed in this study, i.e., an S-Test measuring content based English achievement and a Persian Social Capital Scale.

\subsubsection{Achievement Test}

Based on the argument that the words/phrases constituting a given text are the schemata whose understanding depends on their semantic, syntactic and discoursal relationships with each other, Khodadady $(1997,1999)$ and Khodadady and Herriman (2000) suggested a number of these contextual words/schemata be chosen rationally, deleted and presented as the keyed responses among schema-based alternatives called competitives. They maintained that the magnitude of test takers' ability to read and comprehend the text can then be objectively measured on the basis of the number of keyed responses they select. Since the competitives chosen to design schema-based cloze multiple choice item tests (MCITs) are related not only to each other but also to other schemata comprising the whole text, they measure both the test takers' background knowledge of the schemata themselves and their semantic, syntactic and discoursal relationships with each other as they are juxtopoased to form the text as a whole. Khodadady (2012) validated the schema-based cloze MCITs both empirically and factorially and named them S-Tests.

One paragraph from each six lessons comprising English book 3 (Birjandi, Nouroozi, \& Mahmoodi, 2010) taught at grade three in Iranian high schools were, therefore, chosen to design an S-Test for this study. Following Khodadady and Elahi (2012) and Khodadady, Pishghadam and Fakhar (2010), thirty five semantic schemata (81.4\%), i.e., nine adjectives $(25.7 \%)$, one adverb (2.9\%), eight nouns $(22.9 \%)$, and 17 verbs $(48.6 \%)$, and eight syntactic schemata $(18.6 \%)$, i.e., one conjunction $(2.3 \%)$, one determiner (2.3\%), two para-adverbs $(4.7 \%)$, three prepositions $(7 \%)$ and one pronoun $(2.3 \%)$, were chosen and deleted from the paragraphs. The deleted schemata were then presented along with three competitives which had semantic, syntactic and discoursal relationships with the keyed responses and the other schemata comprising the paragraphs. (The S-Test is given in Appendix A.)

Table 1 presents the competitives as well as the keyed response of the S-Test item 23 given as an example. As can be seen, the three competitives provide, produce and make are syntactically related to the keyed response prepare in 
being a verb. They are also semantically related to prepare in that they share at least one semantic feature with it, i.e. make. The competitive provide for example, means make something available to someone. However, in order to find out whether it is an appropriate alternative to be chosen or not, the test takers must focus on the schemata education and job used in the immediate discourse and conclude that education by itself cannot provide a job for any person and provide must not, therefore, be chosen. The necessity of taking all the alternatives into account and processing their various relationships with each other as well as the discourse in which they appear make the choices offered with the keyed response competitive and thus distinguish them from their traditional counterparts, i.e., distracters.

\subsubsection{Social Capital Scale}

The Persian 40-item Social Capital Scale (SCS) developed by Khodadady and Alaee (2012) was employed in this study. (In order to reach more international audience the English version of the SCS is given in Appendix B. Interested readers can, however, contact the corresponding author to obtain its Persian version.) Khodadady and Alaee administered it to one thousand three hundred and fifty two grade three high school students in Mashhad, Iran. As can be seen in Table 2, the SCS is a reliable scale $(\alpha=.89)$ comprising ten factors, i.e., Self Volunteering, Receptive Relatives, Maternal Supervision, Parental Monitoring, Teacher Consultation, Parental Expectation, Parental Rapport, Family Religiosity, Helpful Others, and Parent Availability. The alpha reliability coefficients of these factors range from .73, i.e., Parental Monitoring, to .40, i.e., Parent Availability. While the reliability coefficients of the remaining factors are similar to the former, the latter has a low reliability. However, since only two items loaded acceptably on Parent Availability, its low reliability index sounds justifiable.

\subsection{Procedures}

Upon having the S-Test and SCS printed, the authorities of educational district four were contacted and an official approval for conducting the present research project in their high schools was obtained. After the statistics of the schools in the district was obtained, seven were chosen and their principals and English teachers were contacted in person encouraged to cooperate. Fortunately, the principles of the chosen schools welcomed the projects and their English teachers agreed to talk to their students and announce their readiness upon approval. Having secured a certain date for administration, one of the researchers attended the schools in person and handed out the S-Test and SCS together in one session in 2011.

\subsection{Data Analysis}

The internal consistency of the S-Test was estimated via Cronbach Alpha. In order to determine the internal validity of the test, the facility and discrimination indices of its 43 items were estimated. The item facility (IF) index was calculated by dividing the number of correct answers by the total number of test takers while the item discrimination (ID) index was estimated by correlating the answers given to each item with the total score on the S-Test. The raw scores were also employed to divide the students into high, middle and low achievers. For this purpose, they were converted to standardized values, i.e., z-scores, and the students whose z-scores on the S-Test were equal or higher than +1 and those with $z$-scores of -1 and lower were classified as high and low achievers, respectively. The students whose z-scores fell between -1 and +1 were considered middle achievers. The relationship between students' achievement scores and the SCS as well as its ten factors was explored via Person Product Moment Correlation. All the statistical analyses were carried out by utilizing the IBM SPSS Statistics 19.0 to explore the following research hypotheses.

H1. The SCS will correlate significantly with the S-Test and its semantic as well as syntactic subtests.

H2. The ten factors underlying the SCS will correlate significantly with the S-Test and its semantic as well as syntactic subtests.

\section{Results and Discussion}

Table 3 presents the descriptive statistics of the S-Test and its semantic and syntactic subtests. As can be seen, not only the S-Test itself but also its semantic subtest are highly reliable $(\alpha=.94$ and .93 , respectively.) The syntactic subtest, however, has a low reliability coefficient, i.e., $\alpha=.66$, because it consists of only eight items whose mean IF, i.e., .62, is lower than the S-Test, i.e., .67, and its semantic subtest, i.e., .69, indicating that it was more difficult than the two. Similarly, the mean ID value of the syntactic subtest, i.e., .46, is lower than that of S-Test, i.e., .52, and semantic subtest, i.e., .54. Fewer items, higher difficulty level and lower discrimination power have, therefore, rendered the reliability of the syntactic subtest low.

Table 4 presents the IF and ID indices of the S-Test. As can be seen, out of 43 items, 37 (86\%) have functioned well because their IFs are between .25 and .75 and their IDs are .20 and higher. As an index of well functioning items, Baker (1989) suggested IDs lower than .30 be discarded whereas Madsen (1983) believed that an ID of .15 or higher should be accepted. Khodadady $(1997,1999)$, however, adopted .20 and higher as IDs of well functioning item 
because they proved to be more discriminating among small number of native and non-native test takers. The results given in Table 4 show that achievement S-Tests enjoy high discrimination power because the lowest ID on the $\mathrm{S}$-Test designed in this study was .25 , i.e., item 2 . Furthermore, it enjoys a high level of internal validity because 86 percent of its items have acceptable IFs and IDs.

Table 5 presents the descriptive statistics of low, middle and high achievers' performance on the S-Test. As can be seen, the high achievers' mean score on the test is the highest, i.e., 41.46. One Way ANOVA analysis of the means obtained by the three groups of achievers showed that they were significantly different, i.e., $\mathrm{F}=829.766, \mathrm{df}=2, p$ $<.001$. The Scheffe Post Hoc Test indicated that the high achievers' scores on the S-Test differed significantly not only from the middle but also low achievers and thus confirmed the adoption of z-scores as significant measures of ability distinctions made among test takers on the basis of their English achievement.

Table 6 presents the correlation coefficients (CCs) obtained among the scores of all, high, middle and low achievers on the S-Test, its subtests, the SCS and its ten factors. As can be seen, social capital does not show any significant relationship with students' achievement as measured by the S-Test (ST). Neither do the semantic (SEM) and syntactic (SYN) subtests of the ST correlate significantly with the SCS. These results disconfirm the first hypothesis that the SCS will correlate significantly with the S-Test and its semantic as well as syntactic subtests. They indicate that grade three high school students' social capitals do not play any significant role in the learning of global concepts presented via English semantic schemata which are connected to each other by English syntactic schemata as texts. These findings are in sharp contrast to the significant correlation coefficient, i.e., $\mathrm{r}=.19, p<.01$, found by Khodadady and Zabihi (2011) between the 219 university students' social capitals who were majoring in English and their high school diploma GPAs.

Similar to the SCS, its latent variables do not correlate significantly with the achievement test. Nor do they relate significantly to the two subtests of the S-Test, disconfirming the second hypothesis that the ten factors underlying the SCS will correlate significantly with the S-Test and its semantic as well as syntactic subtests. These findings are in contrast to those of Khodadady and Zabihi (2011) who reported significant correlations between their SCS and three of its eight factors, i.e., Parental Consultation $(\mathrm{r}=.21, p<.01)$, Family Support $(\mathrm{r}=.14, p<.05)$, and Parent-School Encouragement and Facility $(\mathrm{r}=.34, p<.01)$, with the GPAs of participants majoring in English. The difference in the findings stem not only from participants' level of education, i.e., grade three high school students vs. university students but also from ability indicators, i.e., English achievement vs. GPAs.

The SCS does not relate to grade three high school students' performance either on the S-Test or on its SEM and SYN subtests when the students are divided into high, middle and low achievers on the basis of their total scores on the S-Test. The eighth factor of the SCS, Family Religiosity, however, correlates significantly with high achievers' scores on the S-Test, i.e., $\mathrm{r}=.20, p<.05$, indicating that this factor alone explains four percent of variance in high ability students' English achievement. Since it does not show any significant relationship with the SEM and SYN subtests of the S-Test, it can be deduced that the Family Religiosity of high achievers help them approach semantics and syntax as indistinguishable components of the English language.

Similar to high achievers, low achievers' scores on the S-Test do not show any relationship with the SCS. However, its factor five, i.e., Teacher Consultation correlates significantly but negatively with the low achievers' scores on the semantic subtest of S-Test, i.e., $\mathrm{r}=-.28, p<.05$, explaining about eight percent of variance in their English achievement in a negative direction. This finding suggests that due to their low achievement, these students do not approach their teacher for their advice. Neither do they develop any sort of affective relationship with them to create an intimate school environment to participate in its activities as the items loading on this factor reveal, i.e., 25, 26, 27 , and 28 .

Among the three groups, middle achievers' scores on the S-Test relates significantly only to factor four, i.e., Parental Monitoring $(\mathrm{r}=.15, p<.05)$ and shows that it explain $2.25 \%$ of variance in middle achievers' English achievement. Parental Monitoring also correlates significantly with the semantic subtest of the S-Test $(\mathrm{r}=.14, p$ $<.05$ ), explaining $1.96 \%$ of variance in their learning semantic schemata. These findings indicate that middle achievers benefit the most from their Parental Monitoring to learn English as a holistic system by focusing more on what it offers semantically.

Not only does Parental Monitoring correlate significantly with middle achievers' scores on the semantic subtest of S-Test but also factors five and eight, Teacher Consultation and Family Religiosity, reveal the same degree of positive relationship with the same subtest $(\mathrm{r}=.14, p<.05)$, indicating that middle achievers' learning English is as much related to their consultation with their teachers as it relates to their families' attendance of mosques and participation in religious ceremonies and activities.

In Contrast to Parental Monitoring, Teacher Consultation and Family Religiosity, which correlate significantly with 
the semantic subtest of the S-Test, the sixth and ninth factors, Parental Expectation and Helpful Others, correlate significantly with middle achievers' scores on the syntactic subtest of S-Test $(\mathrm{r}=-.17, p<.01, \mathrm{r}=-.18, p<.01$, respectively). The magnitude of correlation coefficients as well as their direction, i.e., positive vs. negative, show that the more the parents of these achievers expect them to be among the top students, continue their studies and be accepted in a good field at university, and the more they get help from others, the poorer they perform on the syntactic subtest of the S-Test.

\section{Conclusion}

The development and administration of a 43-item schema-based cloze multiple choice item test (S-Test) and a validated 40-item Social Capital Scale (SCS) to 447 grade three high school students in Mashhad, Iran, showed that as an ability measure of English language achievement the S-Test and its semantic as well as syntactic subtests correlate significantly with a number of ten factors underlying the SCS when the students are divided into high, middle and low achievers on the basis of their Z-scores on the S-Test. The SCS did not show any significant relationship with the S-Test for all achievers. Its Family Religiosity and Parental Monitoring factors, however, correlated significantly with high and middle achievers' scores on the S-Test, respectively. These findings indicate that only twenty percent of social capitals contribute to learning English at grade three in state high schools in Iran. Future research must show whether the percentage varies in other grades in general and grade four in particular. The English achievement of grade four high school students plays the most significant role in their lives because it will be instrumental in their getting admitted to universities.

Between the semantic and syntactic subtests of the S-Test, the semantic subtest shows significant and positive relationships with three factors underlying the social capitals of middle achievers, i.e., Parental Monitoring, Teacher Consultation, and Family Religiosity. Two social capital factors, i.e., Parental Expectation and Helpful Others, of the same achievers, however, reveal negative and significant relationships with the syntactic subtest of the S-Test, indicating that while thirty percent of given social capitals contribute positively to learning various concepts expressed in certain English adjectives, adverbs, nouns and verbs as its semantic schemata, twenty percent of social capitals dealing with parents' expectations and people outside family contribute negatively to learning English conjunctions, determiners, para-adverbs, prepositions and pronouns as its syntactic schemata by use of which the semantic schemata are related to each other to convey intended messages.

Compared to high and middle achievers, nine factors underlying social capitals do not play any significantly positive role in low achievers' learning of English at grade three in state high schools. Teacher Consultation, however, correlated negatively with the semantic subtest of the S-Test. The negative and significant correlation between this factor and the semantic subscale which happens to be the highest among the correlation coefficients obtained in this study is alarming in that it shows the more low achievers consult their English teachers, the fewer semantic schemata they learn during their school year. Future research must show whether similar findings will be obtained if this study is replicated with a larger and more representative sample.

\section{References}

Bianchi, S. M., \& Robinson, J. (1997). What did you do today? Children's use of time, family composition, and the acquisition of social capital. Journal of Marriage and Family, 59(2), 332-344.

Birjandi, P., Nouroozi, M., \& Mahmoodi, G. (2010). English book 3. Tehran: Ketabhaye Darsie Iran Publication.

Blaxter, M., Poland, F., \& Curran, M. (2001). Measuring social capital: Qualitative study of how older people relate social capital to health. Final report to the Health Development Agency: London. National Statistics. The measurement of social capital in the United Kingdom. Retrieved October 16, 2010 from http:/www.statistics.gov.uk

Carbonaro, W. (1998). A little help from my friends' parents: Intergenerational closure and educational outcomes. American Journal of Sociology, 94 (Issue supplement), S95-S120.

Dyk, P. H., \& Wilson, S. M. (1999). Family-based social capital considerations as predictors of attainment among Appalachian youth. Sociological Inquiry, 69(3), 477-503.

Furstenberg, F., \& Hughes, M. (1995). Social capital and successful development among at-risk youth. Journal of Marriage and the Family, 57(3), 580-592.

Garmoran, A., \& Lopez, E. M. (2007). Preschool antecedents of mathematics achievement of Latinos: The influence of family resources, early literacy experiences, and preschool attendance. Journal of Behavioral Sciences, 299, 456-471.

Hao, L., \& Bonstead-Burns, M. (1998). Parent-child differences in educational expectations and the academic achievement of immigrant and native students. Sociology of Education, 71, 246-268. 
Hughes, J. (1995). Issues of interpretation. In J. A. Hughes, Wes W. Peter, \& J. Martin (Eds.), Understanding classical sociology. Great Britain: The Cromwell Press, Trowbridge, Wiltshire.

Israel, G. D., Beaulieu, L. J., \& Hartless, G. (2001). The influence of the family and community social capital on educational achievement. Rural Sociology, 66(1), 43-68.

Khodadady, E. (1997). Schemata theory and multiple choice item tests measuring reading comprehension. Unpublished $\mathrm{PhD}$ thesis, the University of Western Australia.

Khodadady, E. (1999). Multiple-choice items in testing: Practice and theory. Tehran: Rahnama.

Khodadady, E. (2012). Validity and Tests Developed on Reduced Redundancy, Language Components and Schema Theory. Theory and Practice in Language Studies, 2(3), xxx-xxx.

Khodadady, E., Pishghadam, R., \& Fakhar, M. (2010). The relationship among reading comprehension ability, grammar and vocabulary knowledge: An experimental and schema-based approach. Iranian EFL Journal, 6(2), $7-49$.

Khodadady, E., \& Alaee, F. F. (2012). Designing and validating a social capital scale within a grade specific context. European Journal of Education Studies, xxx-xxx.

Khodadady, E., \& Elahi, M. (2012). The Effect of Schema-Vs-Translation-Based Instruction on Persian Medical Students' Learning of General English. English Language Teaching, 5(1), 146-165.

Khodadady, E., \& Herriman, M. (2000). Schemata theory and selected response item tests: from theory to practice. In A. J. Kunnan (Ed.), Fairness and validation on language assessment (pp. 201-222). Cambridge: CUP.

Lopez, E. (1996). Social capital and the educational performance of Latino Non-Latino youth: Research Report 11. San Luis Obispo, CA: Julian Samora Research Institute.

McNeal, R. (1999). Parental involvement as social capital: Differential effectiveness on science achievement, truancy, and dropping out. Social Forces, 78(1), 117-144.

Morgan, S., \& Scrensen, A. (1999). Parental networks, social closure, and mathematics learning: A test of Coleman's social capital explanation of school effects. American Sociological Review, 64, 661-681.

Morrow, V. (2001). Using qualitative methods to elicit young people's perspectives on their environments: Some ideas for community health initiatives. Health Education Research, 16(3), 255-268.

Muller, C. (2001). The role of caring in the teacher-student relationship for at-risk students. Sociological Inquiry, 71(2), 241-255.

Muller, C., \& Ellison, C. G. (2001). Religious involvement, social capital, and adolescents' academic progress: Evidence from the National Education Longitudinal Study of 1988. Sociological Focus, 34(2), 155-183.

Onyx, J., \& Bullen, P. (1998). Measuring Social Capital in Five Communities in NSW: A Practitioner's Guide. Sydney: Management Alternatives.

Parcel, T. L., \& Dufur, M. J. (2001). Capital at home and at school: Effects on child social adjustment. Journal of Marriage and the Family, 63, 32-47.

Pong, S. (1998). The school compositional effect of single parenthood on 10th-grade achievement. Sociology of Education, 71, 24-43.

Smith, M. H., Beaulieu, L. J., \& Israel, G. D. (1992). Effects of human capital and social capital on dropping out of high school in the South. Journal of Research in Rural Education, 8(1), 75-87.

Staton-Salazar, R. D., \& Durnbusch, S. M. (1995). Social capital and the reproduction of inequality: Information networks among Mexican-origin high school students. Sociology of Education, 68, 116-132.

White, M. J., \& Glick, J. E. (2000). Generation status, social capital, and the routes out of high school. Sociological Forum, 15(4), 671-691.

Wright, J. P., Cullen, F. T., \& Miller, J. (2001). Family social capital and delinquent involvement. Journal of Criminal Justice, 29(1), 1-9.

Yan, W. (1999). Successful African American students: The role of parental involvement. Journal of Negro Education, 68(1), 5-22. 
Table 1. The immediate discourse and alternatives of an S-Test item

\begin{tabular}{|c|c|c|c|c|}
\hline \multirow[t]{2}{*}{$\begin{array}{l}\text { Immediate } \\
\text { discourse }\end{array}$} & \multicolumn{4}{|c|}{$\begin{array}{l}\text { However, we can say that all of us must be educated. This education should ---(23)--- the } \\
\text { person for the job he can do best. }\end{array}$} \\
\hline & Choice & Schema & Function & Item psychometrics \\
\hline & A & provide & Competitive & $\mathrm{IF}=.66$ \\
\hline \multirow[t]{3}{*}{ Alternatives } & B & produce & Competitive & $\mathrm{ID}=.66$ \\
\hline & $\mathrm{C}$ & prepare* & Keyed response & \\
\hline & $\mathrm{D}$ & make & Competitive & \\
\hline
\end{tabular}

Table 2. Descriptive statistics of the ten factors extracted from the SCS by Khodadady and Alaee (2012)

\begin{tabular}{|l|l|l|l|l|l|l|l|}
\hline No & Factors & $\begin{array}{l}\# \text { of } \\
\text { items }\end{array}$ & Mean & SD & $\boldsymbol{\alpha}$ & $\begin{array}{l}\text { \% } \\
\text { Variance }\end{array}$ & $\begin{array}{l}\text { Cum \% } \\
\text { of Variance }\end{array}$ \\
\hline 1 & Self Volunteering & 6 & 27.67 & 5.598 & .70 & 4.887 & 4.887 \\
\hline 2 & Receptive Relatives & 5 & 18.43 & 5.470 & .65 & 4.843 & 9.730 \\
\hline 3 & Maternal Supervision & 4 & 17.86 & 4.728 & .70 & 4.472 & 14.202 \\
\hline 4 & Parental Monitoring & 4 & 14.72 & 4.907 & .73 & 4.431 & 18.633 \\
\hline 5 & Teacher Consultation & 4 & 13.31 & 4.397 & .63 & 4.393 & 23.026 \\
\hline 6 & Parental Expectation & 5 & 20.12 & 4.416 & .60 & 4.362 & 27.388 \\
\hline 7 & Parental Rapport & 5 & 21.01 & 5.439 & .72 & 3.679 & 31.067 \\
\hline 8 & Family Religiosity & 3 & 12.12 & 3.594 & .66 & 3.458 & 34.525 \\
\hline 9 & Helpful Others & 3 & 9.13 & 3.686 & .64 & 2.984 & 37.510 \\
\hline 10 & Parent Availability & 2 & 7.52 & 2.115 & .40 & 1.775 & 39.285 \\
\hline & SCS & 40 & 161.89 & 27.719 & .89 & & \\
\hline
\end{tabular}

Table 3. Descriptive statistics of the S-Test and its semantic and syntactic subtests

\begin{tabular}{|l|l|l|l|l|l|l|l|l|l|}
\hline Tests & Minimum & Maximum & Mean & SD & Kurtosis & Std. Error & Alpha & $\begin{array}{l}\text { Mean } \\
\text { IF }\end{array}$ & $\begin{array}{l}\text { Mean } \\
\text { ID }\end{array}$ \\
\hline S-Test & 7 & 43 & 29.01 & 10.250 & -1.105 & .223 & .94 & .67 & .52 \\
\hline Semantic & 6 & 35 & 24.06 & 8.644 & -1.109 & .223 & .93 & .69 & .54 \\
\hline Syntactic & 0 & 8 & 4.95 & 2.041 & -.836 & .223 & .66 & .62 & .46 \\
\hline
\end{tabular}

Table 4. Facility and discrimination indices of items comprising the S-Test

\begin{tabular}{|l|l|l|l|l|l|l|l|l|l|l|l|l|l|l|}
\hline No & IF & ID & No & IF & ID & No & IF & ID & No & IF & ID & No & IF & ID \\
\hline 1 & .91 & .38 & 10 & .77 & .53 & 19 & .62 & .62 & 28 & .71 & .59 & 37 & .70 & .69 \\
\hline 2 & .94 & .25 & 11 & .58 & .52 & 20 & .65 & .61 & 29 & .65 & .59 & 38 & .65 & .54 \\
\hline 3 & .84 & .38 & 12 & .60 & .52 & 21 & .70 & .59 & 30 & .70 & .64 & 39 & .57 & .44 \\
\hline 4 & .77 & .55 & 13 & .68 & .53 & 22 & .66 & .58 & 31 & .71 & .46 & 40 & .64 & .53 \\
\hline 5 & .78 & .44 & 14 & .74 & .61 & 23 & .66 & .66 & 32 & .67 & .45 & 41 & .55 & .41 \\
\hline 6 & .81 & .51 & 15 & .71 & .64 & 24 & .70 & .63 & 33 & .70 & .53 & 42 & .62 & .61 \\
\hline 7 & .49 & .43 & 16 & .54 & .33 & 25 & .71 & .62 & 34 & .70 & .48 & 43 & .74 & .46 \\
\hline 8 & .53 & .54 & 17 & .62 & .42 & 26 & .66 & .61 & 35 & .64 & .60 & & & \\
\hline 9 & .69 & .57 & 18 & .51 & .41 & 27 & .46 & .36 & 36 & .67 & .58 & & & \\
\hline
\end{tabular}


Table 5. Descriptive statistics of high, middle and low achievers' scores on the S-Test

\begin{tabular}{|c|c|c|c|c|c|c|c|c|}
\hline \multirow{2}{*}{ Achievers } & \multirow{2}{*}{$\mathbf{N}$} & \multirow{2}{*}{ Mean } & \multirow{2}{*}{ SD } & \multirow{2}{*}{$\begin{array}{l}\text { Std. } \\
\text { Error }\end{array}$} & \multicolumn{2}{|c|}{ 95\% Confidence Interval for Mean } & \multirow{2}{*}{$\begin{array}{l}\text { Minimu } \\
\text { m }\end{array}$} & \multirow{2}{*}{ Maximum } \\
\hline & & & & & Lower Bound & Upper Bound & & \\
\hline Low & 101 & 13.82 & 3.113 & .310 & 13.21 & 14.44 & 7 & 18 \\
\hline Middle & 277 & 30.14 & 6.008 & .361 & 29.43 & 30.85 & 19 & 39 \\
\hline High & 98 & 41.46 & 1.194 & .121 & 41.22 & 41.70 & 40 & 43 \\
\hline Total & 476 & 29.01 & 10.25 & .470 & 28.08 & 29.93 & 7 & 43 \\
\hline
\end{tabular}

Table 6. Correlations between the SCS as well as its factors with three groups of achievers on the S-Test

\begin{tabular}{|c|c|c|c|c|c|c|c|c|c|c|c|c|}
\hline \multirow{2}{*}{ Factor } & \multicolumn{3}{|c|}{ All achievers } & \multicolumn{3}{|c|}{ High achievers } & \multicolumn{3}{|c|}{ Middle achievers } & \multicolumn{3}{|c|}{ Low achievers } \\
\hline & ST & SEM & SYN & ST & SEM & SYN & ST & SEM & SYN & ST & SEM & SYN \\
\hline 1 & .05 & .06 & .01 & -.04 & .03 & -.12 & -.05 & -.04 & -.06 & .06 & .11 & -.07 \\
\hline 2 & -.03 & -.02 & -.06 & .08 & .13 & -.04 & -.03 & -.01 & -.10 & -.01 & -.02 & .02 \\
\hline 3 & .07 & .06 & .08 & .07 & .18 & -.10 & -.05 & -.07 & .03 & .07 & .04 & .10 \\
\hline 4 & -.03 & -.03 & -.02 & .14 & .09 & .13 & $.15^{*}$ & $.14^{*}$ & .09 & -.06 & -.07 & -.00 \\
\hline 5 & .01 & .02 & -.01 & .02 & .02 & .01 & .14 & $.14^{*}$ & -.03 & -.17 & $-.28^{* *}$ & .16 \\
\hline 6 & -.04 & -.03 & -.09 & .08 & .14 & -.03 & -.02 & .03 & $-.17^{* *}$ & -.13 & -.20 & .08 \\
\hline 7 & .02 & .02 & .01 & .06 & .11 & -.05 & -.06 & -.06 & -.03 & .13 & .11 & .08 \\
\hline 8 & .00 & .01 & -.04 & $.20^{*}$ & .15 & .15 & .10 & $.14^{*}$ & -.08 & .07 & .02 & .14 \\
\hline 9 & -.04 & -.02 & -.08 & .05 & .07 & -.01 & -.10 & -.07 & $-.18^{* *}$ & -.17 & -.19 & -.02 \\
\hline 10 & -.04 & -.05 & .01 & .08 & .07 & .05 & -.01 & -.03 & .07 & .06 & .03 & .08 \\
\hline SCS & .01 & .02 & $\begin{array}{l}-.01 \\
\end{array}$ & .11 & .15 & .01 & .02 & .04 & -.06 & -.01 & -.05 & .09 \\
\hline
\end{tabular}

* Correlation is significant at the 0.05 level (2-tailed)

** Correlation is significant at the 0.01 level (2-tailed)

\section{Appendix A}

The S-Test

Today there is a television set in ---(1)---every house. In some countries, you can ---(2)---between as many as forty different channels; some show only a single type of program- news, sports, music, theater or movies; most show different kinds of programs, giving the viewer a lot of ---(3)--- to choose from. In one country, a/an ---(4)--- research showed that the ---(5)--- person spent three and a half hours a day watching television. Housewives were the biggest group of viewers. They ---(6)--- an average of about five hours a day watching TV ---(7)--- their husbands were out at work.

\begin{tabular}{|l|l|l|l|l|}
\hline 1 & A. quite & B. practically & C. almost & D. fairly \\
\hline 2 & A. elect & B. choose & C. pick & D. determine \\
\hline 3 & A. choices & B. decisions & C. opinions & D. elections \\
\hline 4 & A. fresh & B. recent & C. modern & D. current \\
\hline 5 & A. standard & B. routine & C. natural & D. average \\
\hline 6 & A. spent & B. wasted & C. lost & D. passed \\
\hline 7 & A. when & B. while & C. but & D. since \\
\hline
\end{tabular}


What we remember and the way we ---(8)--- it are influenced by our interests, way of thinking and emotional feelings. In fact, we may ---(9)--- completely conscious memory of very important events if they are difficult or ---(10)--- for us. The ---(11)---of large areas of memory ---(12)--- in some mental and physical illnesses. Psychologists have been searching for the chemical ---(13)--- of memory in the brain.

\begin{tabular}{|l|l|l|l|l|}
\hline 8 & A. remind & B. inform & C. think & D. recall \\
\hline 9 & A. miss & B. disappear & C. lose & D. vanish \\
\hline 10 & A. sad & B. painful & C. upset & D. unhappy \\
\hline 11 & A. loss & B. death & C. murder & D. end \\
\hline 12 & A. finds & B. locates & C. occurs & D. discovers \\
\hline 13 & A. key & B. basis & C. value & D. importance \\
\hline
\end{tabular}

In many modern countries it has for some time been ---(14)--- to think that by free education for all- whether rich or poor, clever or stupid- one can ---(15)--- all the problems of society and ---(16)---a perfect nation. But we can ---(17)--- see that free education for all is not enough. We find in ---(18)--- countries a far larger number of people with university degrees than there are jobs for them to ---(19)---. Because of their degrees, they ---(20)--- to do what they think "low" work; and, in fact, they don't like work with the---(21)---. However, we can say that all of us must be ---(22)---. This education should ---(23)--- the person for the job he can do best. We know that all jobs are ---(24)---, and no one should be ashamed ---(25)---one's work.

\begin{tabular}{|c|c|c|c|c|}
\hline 14 & A. stylish & B. hot & C. trendy & D. fashionable \\
\hline 15 & A. solve & B. remedy & C. answer & D. cure \\
\hline 16 & A. produce & B. build & C. create & D. manufacture \\
\hline 17 & A. before & B. yet & C. already & D. still \\
\hline 18 & A. another & B. such & C. other & D. like \\
\hline 19 & A. make & B. cover & C. collect & D. fill \\
\hline 20 & A. refuse & B. forget & C. deny & D. decline \\
\hline 21 & A. machines & B. hands & C. tools & D. devices \\
\hline 22 & A. educating & B. academic & C. studied & D. educated \\
\hline 23 & A. provide & B. produce & C. prepare & D. make \\
\hline 24 & A. practical & B. useful & C. convenient & D. handy \\
\hline 25 & A. on & B. from & C. of & D. at \\
\hline
\end{tabular}

The Olympics ---(26)--- a lot of people every year. This is a competition ---(27)--- many nations of the world. It is ---(28)---every four years. A large number of ---(29)--- from different countries ---(30)--- in the competitions. There are a lot of ---(31)--- like: track and field, swimming, boxing, gymnastics, wrestling and so on.

\begin{tabular}{|l|l|l|l|l|}
\hline 26 & A. draw & B. attract & C. bring & D. tempt \\
\hline 27 & A. between & B. in & C. among & D. inside \\
\hline 28 & A. started & B. held & C. began & D. opened \\
\hline 29 & A. supporters & B. audiences & C. viewers & D. athletes \\
\hline 30 & A. take part & B. appear on & C. bring in & D. get in \\
\hline 31 & A. happenings & B. events & C. situations & D. occasions \\
\hline
\end{tabular}


Computers are used to ---(32)--- different things. They are used in ---(33)--- airplanes and modern cars. All spacecrafts which are ---(34)--- out through space are controlled by computers.

\begin{tabular}{|l|l|l|l|l|}
\hline 32 & A. draw & B. trace & C. design & D. realize \\
\hline 33 & A. wide & B. vast & C. roomy & D. giant \\
\hline 34 & A. orbiting & B. rounding & C. circling & D. surrounding \\
\hline
\end{tabular}

Then Alexander Graham Bell ---(35)--- the telephone. People could talk to ---(36)---even when they were ---(37)---. Everyone thought the new invention was wonderful. When a person ---(38)---a voice speaking ---(39)--- the telephone from miles away, he was too ---(40)--- to say "How do you do?" or "Good morning." But he was also ---(41)---the person at the other end of the ---(42)--- wouldn't hear him if he didn't ---(43)---. So he called out "Hullo". This was a very old word.

\begin{tabular}{|c|c|c|c|c|}
\hline 35 & A. created & B. discovered & C. innovated & D. invented \\
\hline 36 & A. one another & B. the other & C. each other & D. one other \\
\hline 37 & A. far apart & B. far above & C. well apart & D. far behind \\
\hline 38 & A. overheard & B. heard & C. listened & D. carried \\
\hline 39 & A. up & B. in & C. over & D. within \\
\hline 40 & A. excellent & B. dramatic & C. wonderful & D. excited \\
\hline 41 & A. terrified & B. afraid & C. frightening & D. fearful \\
\hline 42 & A. thread & B. cord & C. rope & D. wire \\
\hline 43 & A. shout & B. yell & C. roar & D. cry \\
\hline
\end{tabular}

This is the end of the test.

\section{Appendix B}

The 40 item-Social Capital Scale developed by Khodadady and Alaee (2012)

\begin{tabular}{|l|l|l|l|}
\hline No & Item & Factor & Loading \\
\hline 1 & My mother is often at home. & 10 & 0.42 \\
\hline 2 & My father is often at home. & 10 & 0.32 \\
\hline 3 & My parents encourage me to continue my study. & 6 & 0.34 \\
\hline 4 & I usually talk to my parents about my future feature job and education. & 4 & 0.52 \\
\hline 5 & My mother keeps track of my progress. & 4 & 0.56 \\
\hline 6 & My father keeps track of my progress. & 4 & 0.63 \\
\hline 7 & My parents help me with my homework. & 4 & 0.38 \\
\hline 8 & My parents know where I am and what I do. & 3 & 0.42 \\
\hline 9 & Our family environment is very intimate and warm. & 7 & 0.44 \\
\hline 10 & My parents expect me to be among the top students in my class. & 6 & 0.59 \\
\hline 11 & My parents expect me to be accepted in a very good field at university. & 6 & 0.70 \\
\hline 12 & My friends expect me to be accepted in a good field at university. & 6 & 0.35 \\
\hline 13 & During my education, my mother has taken part in school meetings. & 3 & 0.56 \\
\hline 14 & My mother knows most of my friends. & 3 & 0.56 \\
\hline 15 & My mother supervises my school affairs more than my father. & 3 & 0.68 \\
\hline 16 & I see my grandparents weekly. & 2 & 0.32 \\
\hline
\end{tabular}




\begin{tabular}{|l|l|l|l|}
\hline 17 & I call my friends and acquaintances regularly. & 2 & 0.44 \\
\hline 18 & We regularly visit our relatives. & 2 & 0.68 \\
\hline 19 & We regularly visit our neighbors. & 2 & 0.42 \\
\hline 20 & We have many friends and acquaintances and keep in touch with them. & 2 & 0.64 \\
\hline 21 & My family participates in religious activities (Nazri, Eftari, etc.) & 8 & 0.52 \\
\hline 22 & My family takes part in mourning anniversaries of Emams. & 8 & 0.76 \\
\hline 23 & We go to mosque to worship God. & 8 & 0.45 \\
\hline 24 & I like to get involved in extracurricular activities. & 1 & 0.46 \\
\hline 25 & I participate in school activities. & 5 & 0.44 \\
\hline 26 & Generally, we have intimate school environment. & 5 & 0.44 \\
\hline 27 & I like my teachers. & 5 & 0.49 \\
\hline 28 & I consult with my teachers when I have a problem. & 5 & 0.54 \\
\hline 29 & In my opinion most of the people are trustable. & 9 & 0.44 \\
\hline 30 & When needed, I can easily get help from the others. & 9 & 0.61 \\
\hline 31 & When I want to make a decision, I get help from the others. & 9 & 0.54 \\
\hline 32 & I feel valued by society. & 1 & 0.38 \\
\hline 33 & When needed, I will help my townspeople. & 1 & 0.52 \\
\hline 34 & I know my responsibilities as a citizen and perform them completely. & 1 & 0.50 \\
\hline 35 & I easily talk about my feelings with my parents. & 7 & 0.44 \\
\hline 36 & $\begin{array}{l}\text { My parents trust my school in many ways (providing educational progress, } \\
\text { having a good social, cultural and religious environment, and so on). }\end{array}$ & 7 & 0.35 \\
\hline 37 & While shopping, if I see a friend or an acquaintance I will run to him/her. & 1 & 0.41 \\
\hline 38 & My friends have strong ties with me. & 1 & 0.47 \\
\hline 39 & $\begin{array}{l}\text { As a whole, during my education, I have had excellent schools with high } \\
\text { qualities. }\end{array}$ & 7 & 0.37 \\
\hline 40 & Generally, I am satisfied with my social life. & 7 & 0.54 \\
\hline
\end{tabular}

